\title{
A new hepatitis $E$ virus genotype 2 strain identified from an outbreak in Nigeria, 2017
}

\author{
Bo Wang ${ }^{1}$, Olusola Anuoluwapo Akanbi ${ }^{1}$, Dominik Harms', Olufisayo Adesina', Folakemi Abiodun Osundare ${ }^{1,2}$, \\ Dhamari Naidoo ${ }^{3}$, Isabel Deveaux ${ }^{4}$, Opeayo Ogundirann ${ }^{4}$, Uzoma Ugochukwu ${ }^{4}$, Nwando Mba ${ }^{4}$, \\ Chikwe Ihekweazu ${ }^{4}$ and C.-Thomas Bock ${ }^{1,5^{*}}$ (D)
}

\begin{abstract}
Background: In 2017 the Nigerian Ministry of Health notified the World Health Organization (WHO) of an outbreak of hepatitis $E$ located in the north-east region of the country with 146 cases with 2 deaths. The analysis of the hepatitis $\mathrm{E}$ virus (HEV) genotypes responsible for the outbreak revealed the predominance of HEV genotypes 1 (HEV-1) and 2 (HEV-2). Molecular data of HEV-2 genomes are limited; therefore we characterized a HEV-2 strain of the outbreak in more detail.

Finding: The full-length genome sequence of an HEV-2 strain (NG/17-0500) from the outbreak was amplified using newly designed consensus primers. Comparison with other HEV complete genome sequences, including the only HEV-2 strain (Mex-14) with available complete genome sequences and the availability of data of partial HEV-2 sequences from Sub-Saharan Africa, suggests that NG/17-0500 belongs to HEV subtype 2b (HEV-2b).

Conclusions: We identified a novel HEV-2b strain from Sub-Saharan Africa, which is the second complete HEV-2 sequence to date, whose natural history and epidemiology merit further investigation.
\end{abstract}

Keywords: Hepatitis E virus, HEV genotype 2, HEV subtype 2b, Outbreak, Nigeria, Complete genome

\section{Main text}

Hepatitis E virus (HEV) is the prototype of the family Hepeviridae and a common causative agent of acute viral hepatitis. HEV is a small, (non)enveloped spherical particle of about $34 \mathrm{~nm}$ in diameter harboring a single stranded, positive sense RNA genome of approximately $7.5 \mathrm{~kb}$ [1]. Eight HEV genotypes are recognized within the species Orthohepevirus A based on the pairwise distances of entire viral genomes (HEV-1 to HEV-8). The different HEV genotypes have various reservoirs, distinct distribution, and transmission patterns. Four major HEV

\footnotetext{
* Correspondence: bockc@rki.de; BockC@rki.de

Bo Wang and Olusola Anuoluwapo Akanbi contributed equally to this work. Chikwe Ihekweazu and C.-Thomas Bock contributed equally and thus shared last authorship.

'Division of Viral Gastroenteritis and Hepatitis Pathogens and Enteroviruses, Department of Infectious Diseases, Robert Koch Institute, 13353 Berlin, Germany

${ }^{5}$ Institute of Tropical Medicine, University of Tübingen, 72074 Tübingen Germany

Full list of author information is available at the end of the article
}

genotypes (HEV-1 to HEV-4) are well recognized as human pathogens while HEV-5 and HEV-6 have been detected only in wild boars so far. HEV-7 from dromedary camels has been reported to infect humans and cause chronic hepatitis E. HEV-8 is identified in Bactrian camels with an unknown zoonotic potential [2-4]. HEV-1 and HEV-2 are transmitted through the waterborne/fecal-oral route and responsible for large HEV outbreaks and epidemics in endemic areas like the Indian subcontinent and Africa, whereas HEV-3 and HEV-4 are linked to zoonotic transmission causing sporadic infections mainly in industrialized countries [5]. HEV-2 was firstly identified during a hepatitis E outbreak in Mexico in 1986 while the complete genome sequence (HPENSSP, GenBank accession No. M74506) was subsequently characterized [6]. Recently, additional HEV-2 full-length genome sequences were obtained from an individual patient of same Hepatitis E outbreak in Mexico (Mex-14, KX578717) showing 99.5\%

(c) The Author(s). 2018 Open Access This article is distributed under the terms of the Creative Commons Attribution 4.0 International License (http://creativecommons.org/licenses/by/4.0/), which permits unrestricted use, distribution, and 
nucleotide identity to M74506 [7]. However, the sequences for M74506 and KX578717 are from the same isolate. Since M74506 has been referred to as Mexico [8], Mexico-14 [9], and Telixtac-14 [10], the stool sample was re-analysed at the Paul Ehrlich Institute (PEI), Germany, with the isolate designation Mex-14, and the sequences were submitted to GenBank receiving the accession number KX578717. Additionally, several studies have reported that HEV-2 is distributed in Africa. However, only partial ORF2 gene sequences were amplified [11-14]. According to the report of $\mathrm{Lu}$ et al. and the International Committee on Taxonomy of Viruses (ICTV) Hepeviridae Study Group, Mex-14 is the proposed HEV subtype 2a (HEV-2a) reference sequence,

Table 1 Primers used for HEV quantification, genotyping, and complete genome sequencing

\begin{tabular}{|c|c|c|c|c|}
\hline Primer $^{a}$ & Sequence $\left(5^{\prime}-3^{\prime}\right)$ & Location $^{\mathrm{b}}$ & Use & Reference \\
\hline HEV-07_f & GGTGGTTCTGGGGTGAC & $5261-5278$ & HEV-1 to HEV-4 quantification & {$[18]$} \\
\hline HEV-TM3_f & FAM-TGATTCTCAGCCCTTCGC-MGB & $5284-5301$ & & \\
\hline HEV-08_r & AGGGGTTGGTTGGATGAA & $5330-5313$ & & \\
\hline HEV-38_f & GARGCYATGGTBGAGAARG & $4084-4102$ & HEV-1 to HEV-4 genotyping in ORF1 & {$[18]$} \\
\hline HEV-39_r & GCCATRTTCCARACRGTRTTCC & $4622-4601$ & & \\
\hline HEV-37_f & GGTTYCGYGCYATTGARAARG & $4277-4297$ & & \\
\hline HEV-27_r & TCRCCRGARTGYTTCTTCC & $4583-4565$ & & \\
\hline HEV-30_f & CCGACAGAATTRATTTCGTCGG & $6296-6317$ & HEV-1 to HEV-4 genotyping in ORF2 & \\
\hline HEV-32_f & GTCTCRGCCAATGGCGAGCCRRC & $6350-6372$ & & \\
\hline HEV-31_r & GTYTTRGARTACTGCTGR & $6750-6733$ & & \\
\hline HEV-266_f & GCARGCTGCTCTRGCWGCGGC & $78-98$ & HEV-2 complete genome sequencing & This study \\
\hline HEV-274_f & TGGTGGTTAGGCCTITTCTCTC & $122-143$ & & \\
\hline HEV-275_f & CCGATCCAGCGTGTCATACATA & $223-244$ & & \\
\hline HEV-267_r & GGRGCWGWRTACCARCGCTG & $392-373$ & & \\
\hline HEV-268_f & AYCTYCGYGGYATTAGCTAYAAGG & $1055-1078$ & & \\
\hline HEV-276_r & CGTTGATGGCAAATTGTGAGGT & $1178-1157$ & & \\
\hline HEV-277_f & ATCTCTCGTCTCTACAGCTGGT & $1246-1267$ & & \\
\hline HEV-278_f & GGGCCGTCAGTTGCAATTTTAT & $1299-1320$ & & \\
\hline HEV-283_f & GTAGCTGCCGGACTATTGCT & $1397-1416$ & & \\
\hline HEV-270_r & ARCCACYKCATAAARCARC & $1457-1439$ & & \\
\hline HEV-284_f & ACCAGGGCCATGACAATGAG & $1508-1527$ & & \\
\hline HEV-285_r & GAGGCCTGGTCAGCAACTAG & $2186-2164$ & & \\
\hline HEV-271_f & AACCCMAAGAGGCUYGAGGC & $2620-2639$ & & \\
\hline HEV-272_f & GCCTGGGARCGKAAYCAYCG & $2734-2753$ & & \\
\hline HEV-279_f & TGTTCAACGTAGGATGATCCGG & $2833-2812$ & & \\
\hline HEV-280_f & TTGAGCATACTGGTCTGGTCC & $3220-3241$ & & \\
\hline HEV-273_r & CARCGRUGKGURACAUGCCACC & $3296-3275$ & & \\
\hline HEV-235_r & CYGCCTGGGTGAACACTAG & $3421-3403$ & & \\
\hline HEV-265_f & ATGGGGACGCCTATGATGAATC & $4337-4358$ & & \\
\hline HEV-282_r & TTCTGGGTCGAGTCAAACTCAG & 4439-4418 & & \\
\hline HEV-281_r & CACTCCTCCATAATAGCGCACT & $4481-4460$ & & \\
\hline HEV-286_f & TTCTGCTGTTGCTCCTCCTG & $5169-5188$ & & \\
\hline HEV-301_f & AGACGTCTGGTGTTGCTGAG & $5937-5956$ & & \\
\hline HEV-288_r & TITACTGTCGGCTCGGCATT & $6384-6365$ & & \\
\hline HEV-287_r & GCTGGGCATTCTCCACAGAT & 6413-6394 & & \\
\hline HEV-233_f & GCCTSTITTGTGATGCGCG & $6755-6773$ & & \\
\hline
\end{tabular}

${ }^{a}$ Forward primer designations end with $f$; reverse primer designations end with $r$

${ }^{\mathrm{b}}$ Numbering is according the HEV prototype strain Burma (GenBank accession No. M73218) 
and HEV subtype $2 \mathrm{~b}$ (HEV-2b) was assigned to the partial sequences AF173231 and AF173232 from Nigeria and AY903950 from Chad $[15,16]$.

In June 2017, the Nigerian Ministry of Health reported to the World Health Organization (WHO) an HEV outbreak in north-east Nigeria, with 146 laboratory confirmed cases and two outbreak-associated cases of death in pregnant [17]. In order to identify the corresponding viral pathogens of this hepatitis E outbreak, we determined HEV genotypes from outbreak samples. The genotyping results showed mainly HEV-1 and HEV-2 strains being predominant within the outbreak, the genotype distribution of isolates from this outbreak as determined by the Nigerian center of disease control (NCDC) and Robert Koch Institute (RKI) was 40\% HEV-1 and 60\% HEV-2. However, a number of HEV-positive outbreak samples could not genotyped. Since full-length genome sequences of HEV-2 strains are rare, we here report the full-length genome sequence of the HEV-2 strain (NG/17-0500) from an isolate of the Nigerian outbreak. The virus was detected from an individual from Borno state, Nigeria, and initially tested serologically positive for HEV using Wantai HEV-IgM Rapid Test and Wantai HEV-IgM ELISA (Sanbio, Uden, Netherland).

Viral RNA from an anonymized serum sample (NG/ 17-0500) was extracted using High Pure Viral Nucleic Acid Kit (Roche, Mannheim, Germany) following cDNA synthesis using SuperScript ${ }^{\text {tw }}$ III First-Strand Synthesis System (Invitrogen, Carlsbad, CA, USA) according to the manufacturer's instructions. Molecular approaches with sensitive real-time PCR and consensus nested PCR assays were conducted as described recently [18]. To amplify the entire genome sequence of NG/17-0500 and to verify the geno/subtyping results, universal primers were designed based on 38 complete HEV-1 and HEV-2 sequences from the GenBank database. Using genome walking method, gene-specific primers were designed to amplify the gaps. Primers and probe used are listed in Table 1. The complete viral genome of NG/17-0500 was amplified using KAPA HiFi HotStart

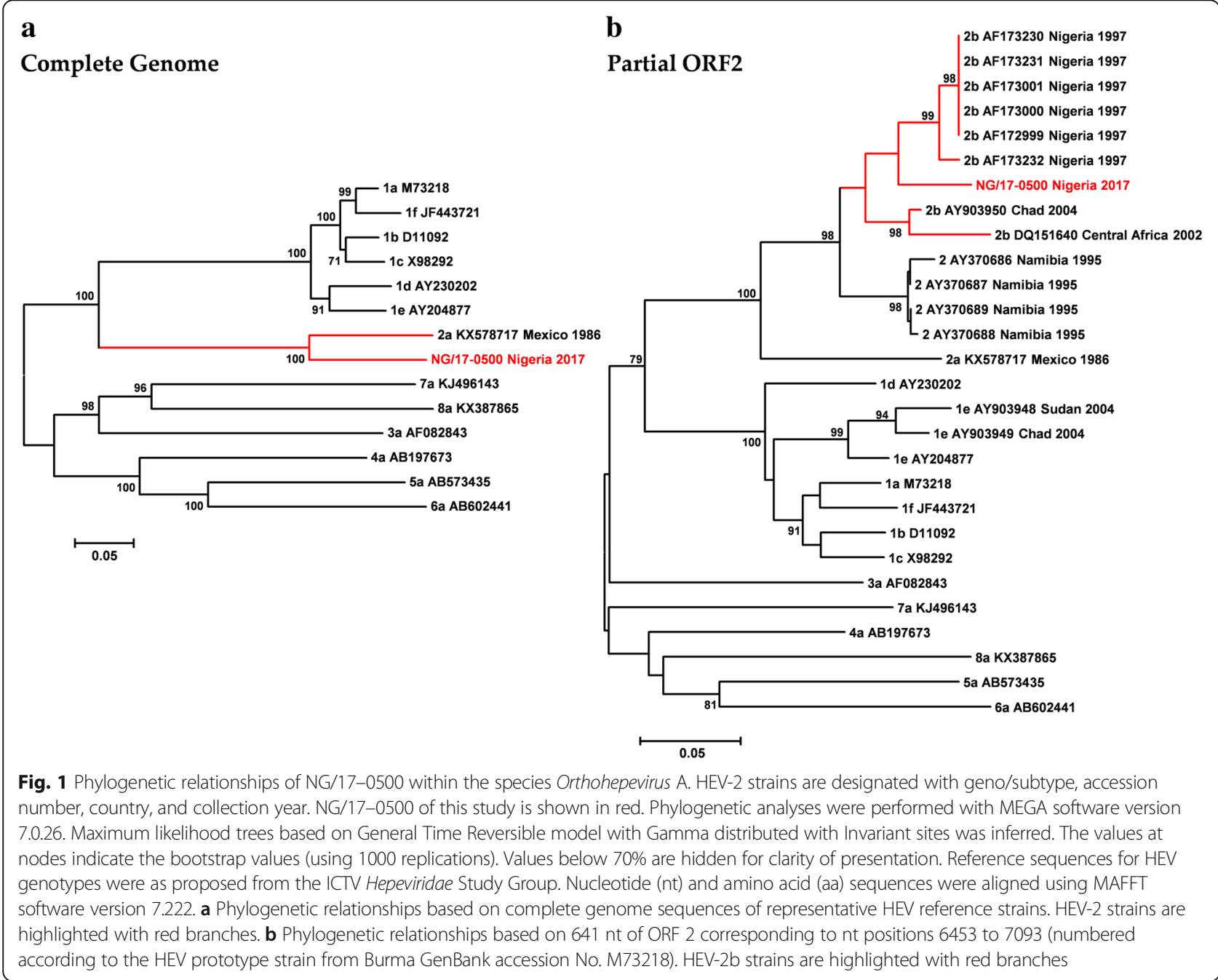


Table 2 Nucleotide and amino acid sequence identities between NG/17-0500 and reference HEV strains within the family Hepeviridae ${ }^{a}$

\begin{tabular}{|c|c|c|c|c|c|c|c|}
\hline \multirow[t]{3}{*}{ Hepeviridae } & \multicolumn{7}{|l|}{ Degree of identity (\%) } \\
\hline & \multirow{2}{*}{$\begin{array}{l}\text { Complete genome } \\
\mathrm{nt}^{\mathrm{b}}\end{array}$} & \multicolumn{2}{|c|}{ ORF1 } & \multicolumn{2}{|l|}{ ORF2 } & \multicolumn{2}{|c|}{ ORF3 } \\
\hline & & $\overline{\mathrm{nt}}$ & aа & $\overline{\mathrm{nt}}$ & aa & $\overline{\mathrm{nt}}$ & aа \\
\hline HEV-1 & 75.0 & 72.3 & 83.5 & 81.0 & 94.8 & 90.9 & 87.8 \\
\hline HEV-2 & 83.5 & 82.3 & 92.7 & 86.8 & 98.2 & 94.1 & 91.1 \\
\hline HEV-3 & 73.1 & 71.2 & 81.5 & 78.7 & 91.2 & 83.9 & 76.4 \\
\hline HEV-4 & 73.5 & 71.1 & 80.6 & 80.7 & 91.1 & 80.6 & 78.9 \\
\hline HEV-5 & 72.6 & 70.1 & 80.1 & 78.6 & 89.1 & 75.0 & 74.1 \\
\hline HEV-6 & 72.8 & 70.9 & 79.4 & 78.0 & 88.5 & 75.5 & 70.5 \\
\hline HEV-7 & 72.3 & 69.8 & 80.6 & 78.8 & 89.8 & 79.0 & 79.8 \\
\hline HEV-8 & 72.2 & 70.0 & 79.9 & 77.9 & 89.4 & 78.5 & 81.6 \\
\hline Avian HEV & 46.3 & 44.9 & 41.3 & 46.2 & 43.3 & 25.6 & 21.1 \\
\hline Rat HEV & 52.1 & 50.1 & 48.0 & 55.1 & 54.8 & 38.1 & 27.1 \\
\hline Bat HEV & 47.2 & 45.8 & 41.6 & 55.1 & 48.1 & 30.6 & 15.9 \\
\hline
\end{tabular}

${ }^{a}$ The sequences were aligned using MAFFT software version 7.222. The evolutionary analyses were conducted using MEGA 7 software version 7.0.26. The GenBank accession numbers are for HEV-1 (M73218), HEV-2 (KX578717), HEV-3 (AF082843), HEV-4 (AJ272108), HEV-5 (AB573435), HEV-6 (AB602441), HEV-7 (KJ496143), HEV-8 (KX387865), Avian HEV (AY535004), Rat HEV (GU345042), and Bat HEV (JQ001749)

${ }^{\mathrm{b}} \mathrm{nt}$ and aa represent nucleotide and amino acid, respectively

ReadyMix PCR kit (Roche, Mannheim, Germany). 5' and $3^{\prime}$ sequences were determined using $5^{\prime}$ and $3^{\prime}$ rapid amplification of cDNA ends (Roche, Mannheim, Germany). Sense and antisense strands of PCR amplicons were sequenced with BigDye Terminator version 3.1 cycle sequencing kit (Thermo Fisher Scientific, USA). Whole genome sequence was assembled and analyzed using Geneious software version 10.0.5. (Biomatters Limited, Auckland, New Zealand) [19].
Real-time PCR assay targeting the HEV ORF2 and ORF3 overlapping region (ORF2/3) demonstrated viremic $\mathrm{HEV}$ infection with a viral load of $1.2 \times 10 \mathrm{E}+$ $7 \mathrm{IU} / \mathrm{mL}$. Sequence analysis of partial ORF1 and ORF2 genes indicated that NG/17-0500 preliminary belongs to HEV-2. After de novo assembly of the amplicons, the NG/17-0500 full-length sequence showed $7198 \mathrm{nu}-$ cleotides, excluding the 3 '-poly (A) tail, with a $\mathrm{G}+\mathrm{C}$ content of $57.5 \%$ harboring the typical $3 \mathrm{HEV}$ ORFs. Phylogenetic analysis of the complete genome sequence revealed that NG/17-0500 grouped with HEV-2 Mex-14 strain (Fig. 1a), and this was all true for phylogenetic analysis of individual ORFs (data not shown). These relationships were also observed for sequence identities between NG/17-500 and other HEV complete genome or nucleotide or amino acid sequence identities of individual ORFs (Table 2).

Due to inadequate sanitation and lack of clean drinking water, hepatitis $\mathrm{E}$ is a severe public health issue in several regions of Africa [20]. Partial HEV-2 sequences have been reported from Sub-Sahara African countries mainly during HEV outbreaks including Namibia in 1995 [12], Sudan in 2004 [13], and the Central African Republic in 2002 [14]. In addition, a single study reported of the analysis of HEV isolates from ten sporadic cases in Port-Harcourt city, southern Nigeria in 1997. Phylogenetic analysis of partial ORF2 fragments indicated that the Nigerian isolates from 1997 are most closely related to the HEV-2a reference Mex-14 strain and have been proposed as HEV-2b $[11,15,16]$. In this regard, comparison of NG/17-0500 sequence to the previously characterized Nigerian HEV-2b isolates displayed a $91.2 \%$ to $92.2 \%$ nt identity. Phylogenetic analysis of the
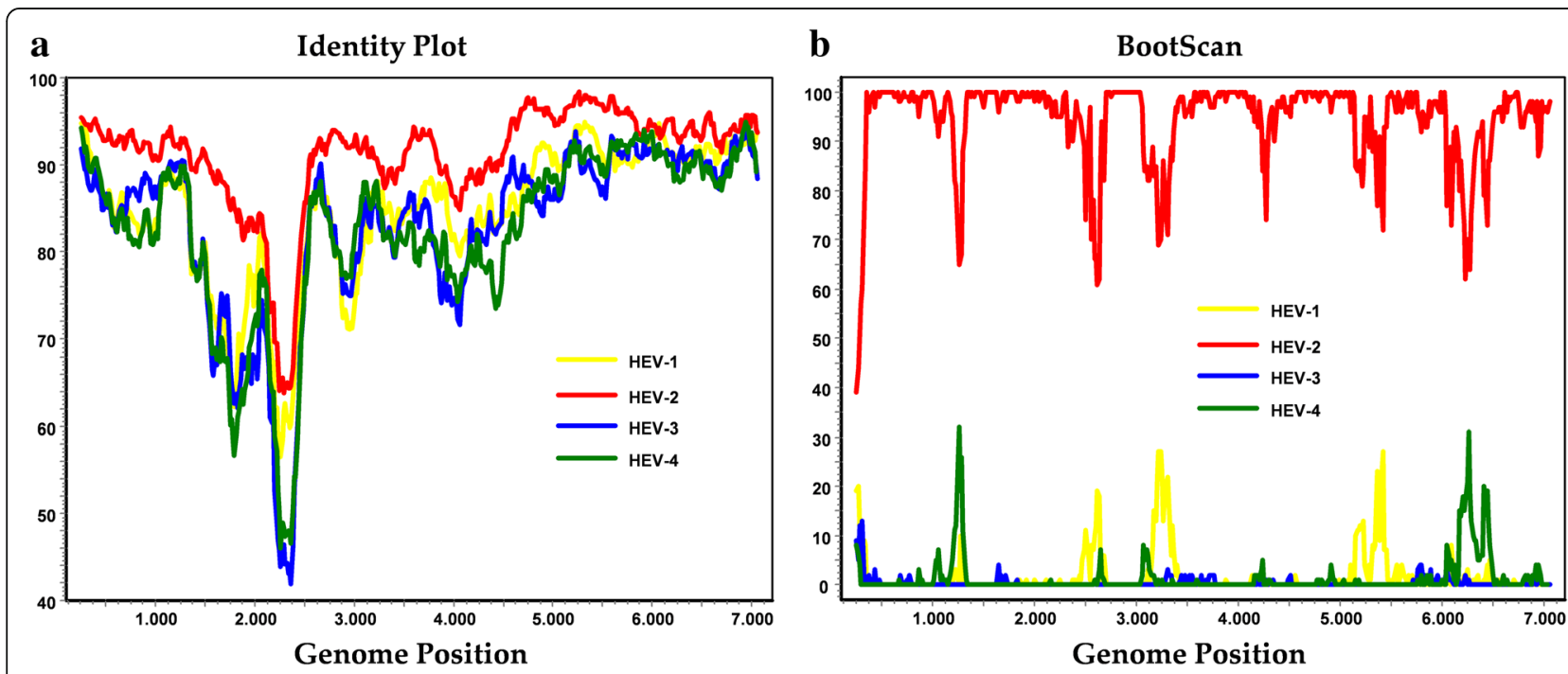

Fig. 2 Detection of potential recombination events of NG/17-0500 within HEV-1 to HEV-4. a Identity Plot and $\mathbf{b}$ BootScan analyses of full-length sequences were performed using SimPlot software program version 3.5 .1 with an F84 distance model, a sliding window size of 300 base pairs and a step size of 15 base pairs increment. Positions containing gaps were stripped from the alignment 
availability of data of partial HEV-2 sequences from Sub-Saharan Africa showed that NG/17-0500 clustered with proposed HEV-2b sequences, indicating NG/170500 belongs to HEV-2b (Fig. 1b). Comparison of partial ORF2 sequences of NG/17-0500 to Chad (AY903950) and Central African Republic (DQ151640) HEV-2b isolates shared $90.3 \%$ and $88.4 \%$ identity, respectively. No evidence of recombination in NG/17-500 was detected by either Identity Plot or Bootscan analysis (Fig. 2). The complete genome sequence of NG/17-0500 has been deposited in GenBank under the accession number MH809516.

In conclusion, to the best of our knowledge the novel HEV-2b strain NG/17-0500 from Nigerian hepatitis E outbreak 2017 represents the first complete HEV-2 genomic sequence from Sub-Sahara Africa and the second complete HEV-2 sequence worldwide, which contributes to our knowledge of the diversity of HEV-2. Nevertheless, the natural history of NG/17-0500 requires further comprehensive genetic and epidemiological analyses.

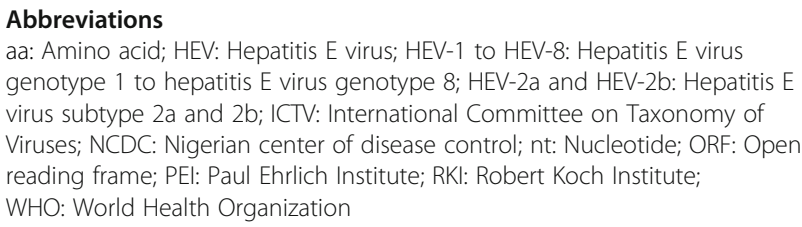
genotype 1 to hepatitis E virus genotype 8; HEV-2a and HEV-2b: Hepatitis E virus subtype 2a and 2b; ICTV: International Committee on Taxonomy of Viruses; NCDC: Nigerian center of disease control; nt: Nucleotide; ORF: Open reading frame; PEl: Paul Ehrlich Institute; RKI: Robert Koch Institute; WHO: World Health Organization

\section{Acknowledgments}

We are grateful for the excellent technical assistance of Marcel Schulze and Steffen Zander (RKI)

\section{Funding}

This research was supported by the Global Outbreak Alert and Response Network (GOARN) Program of the World Health Organisation (WHO). B.W. was funded by the China Scholarship Council (CSC), Beijing, China. O.A.A. is funded by the German Academic Exchange Service (DAAD), Bonn, Germany. D.H. is funded by the Claussen-Simon-Stiftung (Claussen-Simon Foundation) "Dissertation Plus" program, Germany. F.A.O and O.A. are funded by a sub-project of the Global Health Protection Programme supported by the Federal Ministry of Health on the basis of a decision by the German Bundestag, the Partnership in Postgraduate Education (PPE), Robert Koch Institute, Berlin, Germany. The content is the responsibility only of the authors and does not represent the views of the CSC, the DAAD, the Claussen-Simon Foundation, and PPE.

\section{Availability of data and materials}

All data generated or analysed during this study are included in this published article.

\section{Authors' contributions}

$\mathrm{Cl}$ and CTB conceptualized the study. BW, OA, FAO, DH performed the experiment and data analysis. DN, ID, OO, UU, NM collected specimens. BW, $\mathrm{OA}, \mathrm{DH}$ drafted the manuscript. $\mathrm{Cl}$ and $\mathrm{CTB}$ revised the manuscript critically. All authors read and approved the final manuscript.

\section{Ethics approval and consent to participate}

Not applicable. German public health institute (RKI) is authorized to receive blood residuals from diagnostics for surveillance purposes (Infection

Protection Act IfSG §13). All samples analysed were anonymised.

\section{Consent for publication}

Not applicable.

\section{Competing interests}

The authors declare that they have no competing interests. The funders had no role in the design of the study; in the collection, analyses, or interpretation of data; in the writing of the manuscript, and in the decision to publish the results.

\section{Publisher's Note}

Springer Nature remains neutral with regard to jurisdictional claims in published maps and institutional affiliations.

\section{Author details}

'Division of Viral Gastroenteritis and Hepatitis Pathogens and Enteroviruses, Department of Infectious Diseases, Robert Koch Institute, 13353 Berlin, Germany. ${ }^{2}$ Ladoke Akintola University of Technology, Ogbomoso, Oyo State P.M.B 4000, Nigeria. ${ }^{3}$ Infectious Hazard Management Department, World Health Organization, Geneva, Switzerland. ${ }^{4}$ Nigeria Centre for Disease Control, Plot 801, Ebitu Ukiwe Street, Jabi, Abuja, Nigeria. ${ }^{5}$ Institute of Tropical Medicine, University of Tübingen, 72074 Tübingen, Germany.

Received: 12 September 2018 Accepted: 16 October 2018

Published online: 23 October 2018

\section{References}

1. Yin X, Ying D, Lhomme S, Tang Z, Walker CM, Xia N, Zheng Z, Feng Z. Origin, antigenicity, and function of a secreted form of ORF2 in hepatitis $E$ virus infection. Proc Natl Acad Sci U S A. 2018;115(18):4773-8.

2. Purdy MA, Harrison TJ, Jameel S, Meng XJ, Okamoto H, Van der Poel WHM, Smith DB, Ictv Report C. ICTV virus taxonomy profile: Hepeviridae. J Gen Virol. 2017;98(11):2645-6

3. Woo PC, Lau SK, Teng JL, Tsang AK, Joseph M, Wong EY, Tang Y, Sivakumar $\mathrm{S}$, Xie J, Bai R, et al. New hepatitis E virus genotype in camels, the Middle East. Emerg Infect Dis. 2014;20(6):1044-8.

4. Lee GH, Tan BH, Teo EC, Lim SG, Dan YY, Wee A, Aw PP, Zhu Y, Hibberd ML, Tan CK, et al. Chronic infection with camelid hepatitis E virus in a liver transplant recipient who regularly consumes camel meat and milk. Gastroenterology. 2016;150(2):355-7.

5. Wedemeyer H, Pischke S, Manns MP. Pathogenesis and treatment of hepatitis E virus infection. Gastroenterology. 2012;142(6):1388-97.

6. Huang CC, Nguyen D, Fernandez J, Yun KY, Fry KE, Bradley DW, Tam AW, Reyes GR. Molecular cloning and sequencing of the Mexico isolate of hepatitis E virus (HEV). Virology. 1992;191(2):550-8.

7. Kaiser M, Kamili S, Hayden T, Blumel J, Baylis SA. Genome sequence of a genotype 2 hepatitis E virus World Health Organization reference strain. Genome Announc. 2017:5:e01664-16.

8. Purdy MA, Smith DB, Simmonds P, Emerson SU, Harrison T, Meng XJ, Okamoto H, Van der Poel WH, Jameel S. New classification scheme for Hepeviridae. ICTV taxonomic proposal 2014.008a-hV.A.v6.Hepeviridae (approved); 2014. p. 1-15. https://talk.ictvonline.org//taxonomy/.

9. Bradley DW, Balayan MS. Enterically transmitted non-A, non-B hepatitis: etiology of disease and laboratory studies in nonhuman primates. In: Zuckerman AJ, editor. Viral hepatitis and liver disease. New York: Alan R. Liss, Inc.; 1988. p. 138-47

10. Ticehurst J. Identification and characterization of hepatitis $E$ virus. In: Hollinger FB, Lemon SM, Margolis H, editors. Viral hepatitis and liver disease. Baltimore: Williams and Wilkins; 1991. p. 501-3.

11. Buisson $Y$, Grandadam M, Nicand $E$, Cheval P, Van Cuyck-gandre $H$, Innis $B$ Rehel $P$, Coursaget $P$, Teyssou R, Tsarev $S$. Identification of a novel hepatitis E virus in Nigeria. J Gen Virol. 2000:81:903-9.

12. Maila HT, Bowyer SM, Swanepoel R. Identification of a new strain of hepatitis E virus from an outbreak in Namibia in 1995. J Gen Virol. 2004;85: 89-95.

13. Nicand E, Armstrong GL, Enouf V, Guthmann JP, Guerin JP, Caron M, Nizou $J Y$, Andraghetti R. Genetic heterogeneity of hepatitis E virus in Darfur, Sudan, and neighboring Chad. J Med Virol. 2005;77:519-21.

14. Escriba JM, Nakoune E, Recio C, Massamba PM, Matsika-Claquin MD, Goumba C, Rose AM, Nicand E, Garcia E, Leklegban C, Koffi B, Hepatitis E. Central African Republic. Emerg Infect Dis. 2008;14(4):681-3.

15. Smith DB, Simmonds P, Izopet J, Oliveira-Filho EF, Ulrich RG, Johne R, Koenig M, Jameel S, Harrison TJ, Meng XJ, et al. Proposed reference sequences for hepatitis E virus subtypes. J Gen Virol. 2016;97(3):537-42. 
16. Lu L, Li CH, Hagedorn CH. Phylogenetic analysis of global hepatitis E virus sequences: genetic diversity, subtypes and zoonosis. Rev Med Virol. 2006;16:5-36.

17. World-Health-Organization: Acute hepatitis E - Nigeria. Disease outbreak news 2017. http:/www.who.int/csr/don/12-july-2017-hepatitis-e-nigeria/en/. Accessed 7 Sept 2018, released 12 July 2017

18. Wang B, Harms D, Papp CP, Niendorf S, Jacobsen S, Lutgehetmann M, Pischke S, Wedermeyer H, Hofmann J, Bock CT. Comprehensive molecular approach for characterization of hepatitis E virus genotype 3 variants. J Clin Microbiol. 2018;56:e01686-17.

19. Wang B, Yang XL, Li W, Zhu Y, Ge XY, Zhang LB, Zhang YZ, Bock $C T$, Shi ZL. Detection and genome characterization of four novel bat hepadnaviruses and a hepevirus in China. Virol J. 2017;14:40. https://doi.org/10.1186/s12985-017-0706-8.

20. Elduma AH, Zein MMA, Karlsson M, Elkhidir IME, Norder H. A single lineage of hepatitis E virus causes both outbreaks and sporadic hepatitis in Sudan. Viruses-Basel. 2016:8(10):E273.

Ready to submit your research? Choose BMC and benefit from:

- fast, convenient online submission

- thorough peer review by experienced researchers in your field

- rapid publication on acceptance

- support for research data, including large and complex data types

- gold Open Access which fosters wider collaboration and increased citations

- maximum visibility for your research: over $100 \mathrm{M}$ website views per year

At BMC, research is always in progress.

Learn more biomedcentral.com/submissions 